\title{
Clinical profiles of diabetic foot ulcer patients undergoing major limb amputation at a tertiary care center in North-eastern Tanzania
}

Ahmed Shabhay ${ }^{1,2,3^{*}}$, Pius Horumpende ${ }^{3,7}, Z^{2}$ arina Shabhay ${ }^{6}$, Andrew Mganga ${ }^{4}$, Jeff Van Baal ${ }^{5,8}$, David Msuya ${ }^{1,2}$, Kondo Chilonga ${ }^{1,2}$ and Samwel Chugulu ${ }^{1,2}$

\begin{abstract}
Background: Diabetic foot ulcers complications are the major cause of non-traumatic major limb amputation. We aimed at assessing the clinical profiles of diabetic foot ulcer patients undergoing major limb amputation in the Surgical Department at Kilimanjaro Christian Medical Centre (KCMC), a tertiary care hospital in North-eastern Tanzania.

Methods: A cross_-sectional hospital-based study was conducted from September 2018 through March 2019. Demographic data were obtained from structured questionnaires. Diabetic foot ulcers were graded according to the Meggitt-Wagner classification system. Hemoglobin and random blood glucose levels data were retrieved from patients'files.
\end{abstract}

Results: A total of 60 patients were recruited in the study. More than half $(31 / 60 ; 51.67 \%)$ were amputated. Thirty-five (58.33\%) were males. Fifty-nine (98.33\%) had type II diabetes. Nearly two-thirds (34/60; 56.67\%) had duration of diabetes for more than 5 years. The mean age was $60.06 \pm 11.33$ years (range 30-87). The mean haemoglobin level was $10.20 \pm 2.73 \mathrm{~g} / \mathrm{dl}$ and $9.84 \pm 2.69 \mathrm{~g} / \mathrm{dl}$ among amputees. Nearly two thirds $(42 / 60 ; 70.00 \%)$ had a haemoglobin level below $12 \mathrm{~g} / \mathrm{dl}$, with more than a half (23/42; 54.76\%) undergoing major limb amputation. Two thirds (23/31; 74.19\%) of all patients who underwent major limb amputation had mean hemoglobin level below $12 \mathrm{~g} / \mathrm{dl}$. The mean Random Blood Glucose (MRBG) was $13.18 \pm 6.17 \mathrm{mmol} / \mathrm{L}$ and $14.16 \pm 6.10 \mathrm{mmol} / \mathrm{L}$ for amputees. Almost two thirds of the study population i.e., 42/60(70.00\%) had poor glycemic control with random blood glucose level above $10.0 \mathrm{mmol} / \mathrm{L}$. More than half $23 / 42(54.76 \%)$ of the patients with poor glycemic control underwent some form of major limb amputation; which is nearly two thirds $(23 / 31 ; 74.19 \%)$ of the total amputees. Twenty-eight (46.67\%) had Meggitt-Wagner classification grade 3, of which nearly two thirds (17:60.71\%) underwent major limb amputation.

Conclusion: In this study, the cohort of patients suffering from diabetic foot ulcers treated in a tertiary care center in north-eastern Tanzania, the likelihood of amputation significantly correlated with the initial grade of the Meggit-Wagner ulcer classification. High blood glucose levels and anaemia seem to be also important risk factors but correlation did not reveal statistical significance.

Keywords: Amputation, Diabetic foot ulcers, Glycemic control, Anaemia, Meggitt-wagner classification, Tanzania

*Correspondence: ahmed.shabhay@kcmuco.ac.tz

1 Department of General Surgery, Kilimanjaro Christian Medical University College, P.O. Box 2240, Moshi, Tanzania

Full list of author information is available at the end of the article

\section{Background}

Diabetic foot (DF) is defined as infection, ulceration, or destruction of tissues of the foot of a person with currently or previously diagnosed diabetes mellitus [1]. DF 
is usually accompanied by neuropathy and/or peripheral arterial disease (PAD) in the lower extremity. Diabetic foot ulcer is a foot ulcer in a person with diabetes mellitus [1] and about $8-20 \%$ of the diabetics experience a foot ulcer in their lifetime [2]. Compared to other foot ulcers, diabetic foot ulcers have $15-45 \%$ higher risk of amputation of a limb [2] and contribute to nearly $40-70 \%$ of all non-traumatic amputations [3, 4]. In Tanzania, Chalya et al. observed that nearly half $(68 / 162 ; 41.9 \%)$ of the study population who underwent major limb amputation were due to complications of diabetic foot ulcers [5].

It is still not clearly understood which factors play a major role in diabetic foot ulcer patients undergoing major limb amputations [6-8] nor what role neuropathy, peripheral vascular disease, and ulcers each play in pathophysiology of major limb amputations [8]. Documented risk factors do not clearly distinguish those contributing to minor or major limb amputation [6]. However peripheral neuropathy, ulceration, infection, and peripheral vascular disease [7, 9], ischaemic ulcers $[6,7]$ occurring early in diabetics have been identified as principal factors [6] with male sex [6,9], size of ulcer, diabetic nephropathy [7], previous ulcer history, hypertension status, poor glycemic control $[6,7]$ and dyslipidemia [6] also playing a role in amputation of diabetic ulcers [4]. It should be noted that study designs, genetic profiles, ethnicity [8],state of health care system [6] and cultural characteristics might influence the discrepancies observed from different authors [7].

In patients undergoing major limb amputation, age at enrollment, male gender, type two diabetes, high body mass index, poor glycemic control, hypertension, peripheral sensory neuropathy and peripheral vascular disease were the high risk clinical profiles identified by Kantanka et al. in a study in West Africa [10]. In a study at Bugando Medical Centre, a University teaching hospital in Northwestern Tanzania, Chalya et al. observed Meggitt-Wagner Grade 4 ulcers patients were significantly more likely to undergo major limb amputation [11].

Major limb amputation (Transtibial/below knee and transfemoral/above knee amputation) $[1,4]$ is a last resort lifesaving procedure in the management of diabetic foot ulcers patients. Loss of a limb in settings where prosthetics availability is scares or financially restrictive as in Low and Middle Income countries like Tanzania leads to socio, economic and psychological effects to the surrounding patients community as a whole [5] with only half of the amputated diabetic patients having satisfactory rehabilitation [6].

Little is known on clinical profiles of the amputated diabetic foot ulcer patients in North-eastern Tanzania. We set out to determine the clinical profiles of patients who underwent major limb amputations at our centre to provide data needed for planning intervention in prevention of amputation among the diabetic foot ulcer patients.

\section{Materials and methods}

This was a cross sectional study done in the Department of General Surgery, Kilimanjaro Christian Medical Centre, Moshi Tanzania for a period of six months from September 2018 through March 2019. A convenient sampling was done. Diabetic foot ulcer patients admitted in the Surgical department were all included during the study period.

Enrolment in the study required the patient to be above 18 years, be diagnosed with diabetes and an ulcer below the malleolus, with blood work up of haemoglobin and random blood glucose, with known information on age, duration of diabetes, type of anti-diabetic medication, previous history of amputation, hypertensive status, foot involved, duration of ulcer and an informed consent. Non-diabetic patients with foot ulcers of other etiologies were not included.

Diabetic foot ulcers were graded according to the Meggitt-Wagner classification and managed by glycemic control, daily dressings, debridement, disarticulation and amputation when necessary.

During dressing, the gauze covering the wound was irrigated with Normal saline to loosen its attachment to the underlying tissues to reduce trauma and bleeding. Upon removal of the gauzes the wound is irrigated with normal saline, minimal sloughs removed bed-side by surgical blade under local anaesthesia, gentle cleaning by normal saline-soaked wet gauze, drying of the wound with sterile dry gauze and then finally dressing up the wound. The gauzes are kept in place by zinc oxide plasters. Debridement techniques used were Surgical and sharp using scalpel. The types of amputation were either transtibial or transfemoral.

\section{Data management and statistical analysis}

Data were collected using a structured questionnaire. Categorical data were expressed as proportions or percentages. Meggitt-Wagner Classification ulcer grading and outcomes of debridement, disarticulation or amputation were determined from clinical notes/post-operative notes upon discharge. Comparisons between proportions were done using Chi square or Fischer's exact test. A p value of less than or equal to 0.05 at $95 \%$ confidence interval was considered statistically significant.

\section{Ethical considerations}

The study proposal was submitted, reviewed and approved by the Kilimanjaro Christian Medical 
University College Research and Ethical Committee (CREC) and granted certificate number 2366.

The study was conducted according to the ethical principles for medical research in accordance to the Declaration of Helsinki. Confidentiality was ensured in that no personal identifying information was written in the data capture or database. No individual person's data in any form (including any individual details, images or videos) were included. Written informed consent to participate in the study was obtained from study participants. Participants were clearly made to understand that not participating in the study would in no way jeopardize clinical management in the ward.

\section{Results}

\section{Demographic characteristics}

A total of 60 patients were recruited in the study. Thirty-five $(58.33 \%)$ were males. The mean age was $60.06 \pm 11.33$ years (range $30-87$ ) Table 1.

\section{Clinical characteristics}

The mean haemoglobin level was $10.20 \pm 2.73$ and $9.84 \pm 2.69 \mathrm{~g} / \mathrm{dl}$ for patients undergoing major limb amputation. The mean random blood glucose was $13.18 \pm 6.17 \mathrm{mmol} / \mathrm{L}$ and $14.16 \pm 6.10 \mathrm{mmol} / \mathrm{L}$ for amputees Table 2. Fifty-nine (98.33\%) patients were diagnosed with diabetes type II. Nearly two-thirds
$34(56.67 \%)$ had duration of diabetes for more than 5 years. More than half $(31 / 60 ; 51.67 \%)$ of the patients were amputated, nearly a quarter $(21 / 60 ; 35.005)$ needed debridement with only $(8 / 60 ; 13.33 \%)$ undergoing disarticulation of digits. Nearly two thirds $(42 / 60$; $70.00 \%)$ had a haemoglobin level below $12 \mathrm{~g} / \mathrm{dl}$, with more than a half $(23 / 42 ; 54.76 \%)$ undergoing major limb amputation. This is almost two thirds $(23 / 31 ; 74.19 \%)$ of all patients who underwent major limb amputation. Almost two thirds i.e., 42/60 (70.00\%) had poor glycemic control with random blood glucose level above $10.0 \mathrm{mmol} / \mathrm{L}$ of which more than half $23 / 42(54.76 \%)$ underwent some form of major limb amputation which is nearly two thirds $(23 / 31 ; 74.19 \%)$ of the total amputees. Thirty-seven $(61.67 \%)$ were not on insulin therapy where more than half $(20 / 37 ; 54.05 \%)$ underwent major limb amputation, this is nearly two thirds $(20 / 31$; $64.52 \%)$ of the total amputees. Fifty-seven (95.00\%) had no prior history of amputation. Almost half, 28 (46.67\%) had Meggit-Wagner classification grade 3, of which nearly two thirds (17:60.71\%) underwent major limb amputation, nearly a quarter $(13 ; 21.67 \%)$ had Meggit-Wagner grade 4 and 1 (1.67\%) had MeggittWagner grade 5, with $100 \%$ amputation rate. A quarter 16 (26.67\%) had Meggitt-Wagner grade 2 and 2 (3.33\%) had Meggitt-Wagner grade 1 with no a mputations. $(P<0.001)$ which is statistically significant Table 3.

Table 1 Demographic characteristics

\begin{tabular}{|c|c|c|c|c|c|}
\hline Variable & n (\%) & $\begin{array}{l}\text { Amputation } \\
\mathrm{n}(\%)\end{array}$ & $\begin{array}{l}\text { Debridement } \\
\text { n (\%) }\end{array}$ & $\begin{array}{l}\text { Disarticulation } \\
\text { n (\%) }\end{array}$ & $P$-value \\
\hline Age in years (mean(SD)) & $60.06(11.33)$ & $58.03(8.33)$ & $61.16(13.34)$ & $65.50(14.94)$ & $\mathrm{n} / \mathrm{a}$ \\
\hline \multicolumn{6}{|l|}{ Age in years } \\
\hline$\leq 40$ years & $1(1.67)$ & $0(0.00)$ & $1(100.00)$ & $0(0.00)$ & 0.416 \\
\hline $41-50$ years & $10(16.67)$ & $5(50.00)$ & $4(40.00)$ & $1(10.00)$ & \\
\hline $51-60$ years & $24(40)$ & $16(66.67)$ & $6(25.00)$ & $2(8.33)$ & \\
\hline$>60$ years & $25(41.67)$ & $10(40.00)$ & $10(40.00)$ & $5(20.00)$ & \\
\hline \multicolumn{6}{|l|}{ Sex } \\
\hline Female & $25(41.67)$ & $13(52.00)$ & $9(36.00)$ & $3(12.00)$ & $>0.999$ \\
\hline Male & $35(58.33)$ & $18(51.43)$ & $12(34.29)$ & $5(14.29)$ & \\
\hline Total & $60(100.00)$ & $31(51.67)$ & $21(35.00)$ & $8(13.33)$ & \\
\hline
\end{tabular}

Table 2 Means of continuous variables versus outcome

\begin{tabular}{|c|c|c|c|c|}
\hline Variable & $\begin{array}{l}\text { Overall } \\
\text { Mean }( \pm S D)\end{array}$ & $\begin{array}{l}\text { Amputation } \\
\text { Mean( } \pm S D)\end{array}$ & $\begin{array}{l}\text { Debridement } \\
\text { Mean( } \pm \text { SD) }\end{array}$ & $\begin{array}{l}\text { Disarticulation } \\
\text { Mean }( \pm S D)\end{array}$ \\
\hline Age in years & $59.75(11.45)$ & $58.19(8.41)$ & $59.86(13.61)$ & $65.50(14.94)$ \\
\hline Hemoglobin (g/dl) & $10.20(2.73)$ & $9.84(2.69)$ & $10.48(2.92)$ & $10.88(2.43)$ \\
\hline $\mathrm{RBG}(\mathrm{mmol} / \mathrm{l})$ & $13.81(6.17)$ & $14.16(6.10)$ & $14.16(6.50)$ & $11.53(5.81)$ \\
\hline
\end{tabular}


Table 3 Clinical characteristics versus outcomes

\begin{tabular}{|c|c|c|c|c|c|}
\hline Variable & n (\%) & $\begin{array}{l}\text { Amputation } \\
\mathrm{n}(\%)\end{array}$ & $\begin{array}{l}\text { Debridement } \\
\text { n (\%) }\end{array}$ & $\begin{array}{l}\text { §Disarticulation } \\
\text { n (\%) }\end{array}$ & $P$-value \\
\hline \multicolumn{6}{|l|}{ DM type } \\
\hline Type I & $1(1.67)$ & $0(0.00)$ & $1(100.00)$ & $0(0.00)$ & \multirow[t]{2}{*}{0.483} \\
\hline Type ॥ & $59(98.33)$ & $31(52.54)$ & $20(33.90)$ & $8(13.56)$ & \\
\hline \multicolumn{6}{|c|}{ Duration of DM in years } \\
\hline$<1$ & $5(8.33)$ & $1(20.00)$ & $2(40.00)$ & $2(40.00)$ & \multirow[t]{3}{*}{0.118} \\
\hline $1-5$ & $21(35.00)$ & $12(57.14)$ & $5(23.81)$ & $4(19.05)$ & \\
\hline$>5$ & $34(56.67)$ & $18(52.94)$ & $14(41.18)$ & $2(5.88)$ & \\
\hline \multicolumn{6}{|c|}{ Antidiabetic agent } \\
\hline Injection & $23(38.33)$ & $11(47.83)$ & $10(43.48)$ & $2(8.70)$ & \multirow[t]{3}{*}{0.66} \\
\hline Oral & $32(53.33)$ & $18(56.25)$ & $9(28.13)$ & $5(15.63)$ & \\
\hline Herbal & $5(8.33)$ & $2(40.00)$ & $2(40.00)$ & $1(20.00)$ & \\
\hline \multicolumn{6}{|c|}{ Prior history of amputation } \\
\hline No & $57(95.00)$ & $30(52.63)$ & $19(33.33)$ & $8(14.04)$ & \multirow[t]{2}{*}{0.715} \\
\hline Yes & $3(5.00)$ & $1(33.33)$ & $2(66.67)$ & $0(0.00)$ & \\
\hline \multicolumn{6}{|c|}{ Meggitt-Wagner classification } \\
\hline 1 & $2(3.33)$ & $0(0.00)$ & $2(100.00)$ & $0(0.00)$ & \multirow[t]{5}{*}{$<0.001$} \\
\hline 2 & $16(26.67)$ & $0(0.00)$ & $10(62.50)$ & $6(37.50)$ & \\
\hline 3 & $28(46.67)$ & $17(60.71)$ & $9(32.14)$ & $2(7.14)$ & \\
\hline 4 & $13(21.67)$ & $13(100.00)$ & $0(0.00)$ & $0(0.00)$ & \\
\hline 5 & $1(1.67)$ & $1(100.00)$ & $0(0.00)$ & $0(0.00)$ & \\
\hline \multicolumn{6}{|c|}{ Haemoglobin (g/dl) } \\
\hline$<7$ & $8(13.33)$ & $4(50.00)$ & $3(37.50)$ & $1(12.50)$ & \multirow[t]{4}{*}{0.525} \\
\hline 07-10 & $23(38.33)$ & $15(65.22)$ & $7(30.43)$ & $1(4.35)$ & \\
\hline$>10-12$ & $11(18.33)$ & $4(36.36)$ & $4(36.36)$ & $3(27.27)$ & \\
\hline$>12$ & $18(30.00)$ & $8(44.44)$ & $7(38.89)$ & $3(16.67)$ & \\
\hline \multicolumn{6}{|c|}{$\mathrm{RBG}(\mathrm{mmol} / \mathrm{l}))$} \\
\hline$<10$ & $18(30.00)$ & $8(44.44)$ & $7(38.89)$ & $3(16.67)$ & \multirow[t]{3}{*}{0.94} \\
\hline $10-19$ & $28(46.67)$ & $15(53.57)$ & $9(32.14)$ & $4(14.29)$ & \\
\hline$\geq 20$ & $14(23.33)$ & $8(57.14)$ & $5(35.71)$ & $1(7.14)$ & \\
\hline \multicolumn{6}{|c|}{ Hypertensive } \\
\hline No & $34(56.67)$ & $18(52.94)$ & $11(32.35)$ & $5(14.71)$ & \multirow[t]{2}{*}{0.877} \\
\hline Yes & $26(43.33)$ & $13(50.00)$ & $10(38.46)$ & $3(11.54)$ & \\
\hline \multicolumn{6}{|c|}{ duration of ulcers (months) } \\
\hline$<1$ & $40(66.67)$ & $22(55.00)$ & $13(32.50)$ & $5(12.50)$ & \multirow[t]{3}{*}{0.744} \\
\hline$\geq 1$ & $20(33.33)$ & $9(45.00)$ & $8(40.00)$ & $3(15.00)$ & \\
\hline Total & $60(100.0)$ & $31(51.67)$ & $21(35.00)$ & $8(13.33)$ & \\
\hline
\end{tabular}

$\S$ loss of foot digits or part of it

\section{Discussion}

We set out to describe the clinical profiles of diabetic foot ulcer patients who underwent major limb amputations as part of their clinical management admitted in the surgical department of KCMC, a tertiary care and a University teaching hospital in north-eastern Tanzania. It is important to identify factors contributing to amputation among diabetic foot ulcers patients for intervention. In this study population anemia $(23 / 31 ; 74.19 \%)$, poor glycemic control $(23 / 31 ; 74.19 \%)$ and Meggit-Wagner's ulcer grade 3 and above (42/60; 70.00\%) were risk factors for major limb amputation.

In our study $18 / 60(30.00 \%)$ patients had random blood glucose of less than $10.0 \mathrm{mmol} / \mathrm{L}$ on admission. Almost two thirds i.e., $42 / 60(70.00 \%)$ of the study population had poor glycemic control medically with random blood glucose level above $10.0 \mathrm{mmol} / \mathrm{L}$ Table 3 . This is a high blood glucose level that may explain why these patients developed diabetic ulcers. The recommended glycemic targets in non-pregnant diabetics are 
a pre-prandial capillary plasma glucose of $80-130 \mathrm{mg} /$ $\mathrm{dL}(4.4-7.2 \mathrm{mmol} / \mathrm{L})$ or peak postprandial capillary plasma glucose $<180 \mathrm{mg} / \mathrm{dL}(10.0 \mathrm{mmol} / \mathrm{L})$ [12]. Of the $42 / 60$ (70.00\%) patients with poor glycemic control, more than half $23 / 42(54.76 \%)$ underwent some form of major limb amputation. A total of 31 patients underwent some form of major limb amputation. Poor glycemic control contributed to nearly two quarters (23/31; $74.19 \%$ ) of the total amputees. In the diabetic population chronic hyperglycemia leads to impaired wound healing due to increased susceptibility to infections, chronic inflammation state, diabetic micro and macroangiopathy leading to diminished vascularity, impaired collagen synthesis, impaired hyaluronan, autonomic dysfunction and abnormality in cell-mediated immunity and phagocytic function [13, 14]. A high glycated hemoglobin also impairs endothelium mediated vasoactive responses. An erythrocyte shape is affected by a high glucose level, making blood more viscous, impeding blood flow and facilitating formation of thrombus thereby increasing the risk of amputation [15]. Thus, Blood glucose control is paramount in healing of ulcers in diabetics [16].

Whilst tight glycemic control is paramount to prevention of both short- and long-term diabetic complications [6] our patients had a poor glycemic control. More than half $32 / 60(53.33 \%)$ were on oral hypoglycemics but had a poor glycemic control. Patients on oral hypoglycemics alone and with a poor control require insulin for adequate control of the blood glucose [17]. Only a quarter $(23 / 60 ; 38.33 \%)$ of our patients were on injectable insulin at the time of presentation. Of the $37 / 60$ (64.52\%) patients who were not on insulin therapy, more than half (20/37; 54.05\%) underwent major limb amputation, this is nearly two thirds $(20 / 31 ; 64.52 \%)$ of the total amputees. We opine that these patients were medically mismanaged and ended in surgery. It has been observed that male diabetic foot ulcer patients not on insulin therapy have increased risk of undergoing a major limb amputation. However a clear cut information on the indications for initiating insulin in diabetic foot ulcers have to be determined [18].
Thus, an effective regimen on the optimal management of a patient has to be individualized depending on their comorbid conditions [12]. The choice of anti-diabetic medication in diabetic foot ulcer patients depends on the severity of infection. However, in a limb threatening foot ulcer, insulin must be initiated [18]. Tight glycemic control is paramount in infection eradication and ulcer healing [6].

In this study, the mean Haemoglobin level was $10.20 \pm 2.73$ and $9.84 \pm 2.69 \mathrm{~g} / \mathrm{dl}$ for patients undergoing major limb amputation. Nearly two thirds of our patients (42/60; 70.00\%) had a haemoglobin level below $12 \mathrm{~g} / \mathrm{dl}$, more than a half of these anemic (23/42; 54.76\%) undergoing major limb amputation. This is almost two thirds $(23 / 31 ; 74.19 \%)$ of all patients who underwent major limb amputation in our study showing that anaemia was an important factor for amputation Table 3. The World Health Organization cut off point for diagnosis of anaemia is a hemoglobin level of $12.0 \mathrm{~g} / \mathrm{dl}$ for females and $13.0 \mathrm{~g} / \mathrm{dl}$ for males $[19,20]$. Diabetics have a twofold chance of developing anaemia [20-23]. In anemic diabetic foot ulcers patients a poor prognosis of the ulcer healing is evident [21]. Costa et al. had a similar finding where $89.6 \%$ of patients who underwent major limb amputation were anaemic, and anaemia was a significant risk factor for major limb amputation [20, 24]. There is more evidence for a strong association between anaemia and amputation [21]. In diabetic patients with peripheral arterial disease, anaemia further exaggerates the effects of tissue hypoperfusion due to poor oxygen delivery to peripheral tissues and thrombus formation [21].

About half of our patients, 28/60 (46.67\%) had Meggit-Wagner classification grade 3 of which nearly two thirds $(17 / 28 ; 60.71 \%)$ underwent major limb amputation. About a quarter $(13 / 60 ; 21.67 \%)$ had Meggit-Wagner grade 4 and one $(1 / 60 ; 1.67 \%)$ grade 5 of which all underwent major limb amputation Table 3. The Meggitt-Wagner classification system historically is the most frequently used classification system of diabetic foot ulcer $[3,25,26]$. It is a six grade classification system described by Meggitt in 1976 and disseminated by Wagner in 1979 [1] Table 4. In this classification grade 0-3 is

Table 4 Meggit-Wagner ulcer classification system [3]

\begin{tabular}{ll}
\hline Grade & Description \\
\hline 0 & Pre- or post-ulcerative lesion completely epithelialized \\
1 & Superficial, full-thickness ulcer confined to the dermis, not extending to the subcutaneous tissues \\
2 & Ulcer of the skin extending through the subcutaneous tissues with exposed tendon or bone and \\
& without osteomyelitis or abscess formation \\
4 & Deep ulcers with osteomyelitis or abscess formation \\
5 & Localized gangrene of the toes or the forefoot \\
\hline
\end{tabular}


mainly based on neuropathy with grade $4-5$ representing ischaemic lesions [25].It is based on wound depth and tissue viability [26] and assess presence of osteomyelitis [27]. The Meggitt-Wagner classification system grades pre-ulcerative lesions (grade 0); superficial ulcer (grade 1); deep ulcer involving tendon (grade 2); ulcer with bone involvement or abscess (grade 3); limited foot gangrene (grade 4) and whole foot gangrene (grade 5) [27]. It was used in this study due to its predictive value of treatment outcome. It has been observed that Meggit-Wagner grading of diabetic foot ulcer affects and predicts the outcome and the increased risk of amputation [25, 27]. In our study, nearly two thirds of grade 3 ulcer patients and all patients with grade 4 and 5 ulcers underwent major limb amputation. Despite its limitations of not taking into consideration the loss of protective sensation, its inability to differentiate infected and/or ischemic ulcers, with some authors describing the system as imprecise, it has been documented to be able to show association between grade and loss of limb [26]. In our study the MeggittWagner classification system showed an increased amputation risk with higher grades with statistically significant results. Our data give further evidence of the utility and usefulness of the Meggitt-Wagner classification system in predicting major limb amputation among diabetic ulcer patients.

This study had several limitations. It was time bound and focused only on the objectives set. On the surgical management of diabetic foot ulcers, information on microbiological profile of micro-organisms isolated on infected ulcers with their antibiotic sensitivity profile results, presence of osteomyelitis (clinical and radiological), duration of conservative treatment, the mean length of hospital stay, number of previous debridement's prior major limb amputation, indication for amputation, level of amputation, techniques of amputation, and prosthesis supply status is of paramount importance. A study on diabetics, its co-morbidities and its surgical complications is wide and vast, thus in this study, due time and resource limitations, we could only address some risk factors, namely hypertension, Meggitt-Wagner ulcer grade status of patients, haemoglobin levels and blood sugar levels and their association with lower limb amputation. With regards to prosthesis supply, there is an Orthotics and prosthetic department in KCMC hospital, where diabetic foot ulcer patients post amputation after stump healing are referred for prosthesis fitting. A big challenge in our centre is follow-up. Our center caters as a specialized referral hospital for the northern zone of Tanzania. Most of these patients reside from distant localities. Once amputated, they return back to their locality and feedback from them is a challenge. Few return for follow up clinics and prosthesis fitting as it is cost restrictive.

\section{Conclusion}

In this study, the cohort of patients suffering from diabetic foot ulcers treated in a tertiary care center in north-eastern Tanzania, the likelihood of amputation significantly correlated with the initial grade of the MeggitWagner ulcer classification. High blood glucose levels and anaemia seem to be also important risk factors but correlation did not reveal statistical significance.

\section{Abbreviations \\ HbA1c: Glycosylated Hemoglobin; KCMC: Kilimanjaro Christian Medical Centre: MRBG: Mean Random Blood Glucose; PAD: Peripheral Arterial Disease. \\ Acknowledgements \\ KCMC hospital administration for permission to conduct the study, nursing stuff, Intern Doctors who were rotating at General surgical ward (S1) at the time of the study for their support and assisting in the management of the patients and Miss Miriam Titus for her Technical/IT support.}

\section{Authors' contributions}

This work was carried out in collaboration between all authors. AS wrote the research proposal, dissertation thesis and collected the data. SC, JB, KC and DM reviewed the research proposal and dissertation thesis. AS, PH, AM did data analysis and Interpretation. AS and PH prepared the first draft of the manuscript. SC, KC, DM and ZS reviewed and contributed to the final version of the manuscript. All authors have read and approved the final manuscript.

\section{Funding}

The Government of United Republic of Tanzania through its Ministry of Health, Community development, Gender, Elderly and Children provided funding for data collection of this study at Kilimanjaro Christian Medical University College/ Kilimanjaro Christian Medical Centre.

Availability of data and materials

The data used to support this study are available from the first author upon request.

\section{Consent for publication}

Not applicable.

\section{Competing interests}

The authors declare that they have no competing interest.

\section{Author details}

${ }^{1}$ Department of General Surgery, Kilimanjaro Christian Medical University College, P.O. Box 2240, Moshi, Tanzania. ${ }^{2}$ Department of General Surgery, Kilimanjaro Christian Medical Centre, P.O. Box 3010, Moshi, Tanzania. ${ }^{3}$ Institute of Infectious Diseases and Research, Lugalo Military College of Medical Sciences (MCMS) and General Military Hospital (GMH), Mwenge area, P.O. Box 60000, Dar es Salaam, Tanzania. ${ }^{4}$ Department of Public Health, Kilimanjaro Christian Medical University College, P.O. Box 2240, Moshi, Tanzania. ${ }^{5}$ ZGT Academy, Hospital Group Twente, Almelo, Hengelo, The Netherlands. ${ }^{6}$ Department of Neuro-Surgery, Muhimbili Orthopedic Institute, P.O. Box 65474, Dar es Salaam, Tanzania. ${ }^{7}$ Kilimanjaro Clinical Research Institute (KCRI), P.O. Box 2236, Moshi, Tanzania. ${ }^{8}$ Cardiff University, Cardiff, Wales, UK.

Received: 25 October 2020 Accepted: 5 January 2021

Published online: 12 January 2021

\section{Reference:s}

1. van Netten JJ, Bus SA, Apelqvist J, Lipsky BA, Hinchliffe RJ, Game F, et al. Definitions and criteria for diabetic foot disease. Diabetes Metab Res Rev. 2020:36(S1):1-6. 
2. Amjad SS, Zafar J, Shams N. Bacteriology of diabetic foot in tertiary care hospital; frequency, antibiotic susceptibility and risk factors. J Ayub Med Coll Abbottabad. 2017;29(2):234-40.

3. Alexiadou K, Doupis J. Management of diabetic foot ulcers. Diabetes Ther 2012;3(1):1-15

4. Namgoong S, Jung S, Han SK, Jeong SH, Dhong ES, Kim WK. Risk factors for major amputation in hospitalised diabetic foot patients. Int Wound J. 2016;13:13-9.

5. Chalya PL, Mabula JB, Dass RM, Ngayomela IH, Chandika AB, Mbelenge $\mathrm{N}$, et al. Major limb amputations: A tertiary hospital experience in northwestern Tanzania. J Orthop Surg Res. 2012;7(1):1-6.

6. Verrone Quilici MT, Del Fiol FDS, Franzin Vieira AE, Toledo MI. Risk factors for foot amputation in patients hospitalized for diabetic foot infection. J Diabetes Res. 2016:2016:8931508.

7. Shojaiefard A, Khorgami Z, Larijani B. Independent risk factors for amputation in diabetic foot. Int J Diabetes Dev Ctries. 2008;28(2):32-7.

8. Adler A, Boyko E, Ahroni J, Smith D. Lower-extremity amputation in diabetes. Diabetes Care. 1999;22(7):1029-35.

9. Markowitz JS, Gutterman EM, Magee G, Margolis DJ. Risk of amputation in patients with diabetic foot ulcers: A claims-based study. Wound Repair Regen. 2006;14(1):11-7.

10. Sarfo-Kantanka O, Sarfo FS, Kyei I, Agyemang C, Mbanya JC. Incidence and determinants of diabetes-related lower limb amputations in Ghana, 2010-2015-a retrospective cohort study. BMC Endocr Disord. 2019;19(1):27.

11. Chalya PL, Mabula JB, Dass RM, Kabangila R, Jaka H, McHembe MD, et al. Surgical management of Diabetic foot ulcers: a Tanzanian University teaching hospital experience. BMC Res Notes. 2011. https://doi. org/10.1186/1756-0500-4-365.

12. Care D, Suppl SS. Glycemic targets: standards of medical care in diabetes-2020. Diabetes Care. 2020:43(January):S66-76

13. Singh SK, Sridhar GR. Infections and diabetes. Int J Diabetes Dev Ctries. 2015:35(2):59-62

14. Mehraj DM. A review of Wagner classification and current concepts in management of diabetic foot. Int J Orthop Sci. 2018;4(1n):933-5.

15. Salman IN, Wadood SA, Abualkasem BA. Low hemoglobin levels in infected diabetic foot ulcer. IOSR J Pharm Biol Sci. 2017;12(01):05-9.

16. Xiang J, Wang S, He Y, Xu L, Zhang S, Tang Z. Reasonable glycemic control would help wound healing during the treatment of diabetic foot ulcers. Diabetes Ther. 2019;10(1):95-105.

17. Lipscombe L, Booth G, Butalia S, Dasgupta K, Eurich DT, Goldenberg R, et al. pharmacologic glycemic management of type 2 diabetes in adults. Can J Diabetes. 2018;42(Suppl. 1):S88-103.
18. Diabetes in special situations: Insulin in diabetic foot ulcers | diabetes medicinematters.com [Internet]. 2020. https://diabetes.medicinema tters.com/diabetic-foot-ulcers/diabetic-foot-infection/diabetes-in-spec al-situations-insulin-in-diabetic-foot-ulcers/15364250. Accessed 18 Sep 2020.

19. Khusun H, Ray Y, Schultink W, Dillon DHS. World health organization hemoglobin cut-off points for the detection of anemia are valid for an Indonesian population. J Nutr. 1999;129(9):1669-74.

20. Shareef AM, Ahmedani MY, Waris N. Strong association of anemia in people with diabetic foot ulcers (DFUs): Study from a specialist foot care center. Pakistan J Med Sci. 2019;35(5):1216-20.

21. Gezawa ID, Ugwu ET, Ezeani I, Adeleye O, Okpe I, Enamino M. Anemia in patients with diabetic foot ulcer and its impact on disease outcome among Nigerians: results from the MEDFUN study. PLoS ONE. 2019;14(12):1-11.

22. Thomas MC. Anaemia, diabetes and the foot : a short review. 2012;15(4):4-6.

23. Wright JA, Oddy MJ, Richards T. Presence and characterisation of anaemia in diabetic foot ulceration. Anemia. 2015;2014(July):1-8.

24. Costa RHR, Cardoso NA, Procópio RJ, Navarro TP, Dardik A, de Loiola CL. Diabetic foot ulcer carries high amputation and mortality rates, particularly in the presence of advanced age, peripheral artery disease and anemia. Diabetes Metab Syndr Clin Res Rev. 2017;11:S583-7.

25. Praveena DL, Uppin SM, Shimikore SS. A one year cross sectional study on role of Wagner's classification in predicting the outcome in diabetic foot ulcer patients. Int Surg J. 2018;5(7):2537.

26. Monteiro-Soares M, Russell D, Boyko EJ, Jeffcoate W, Mills JL, Morbach S, et al. Guidelines on the classification of diabetic foot ulcers (IWGDF 2019). Diabetes Metab Res Rev. 2020. https://doi.org/10.1002/dmrr.3273.

27. Oyibo SO, Jude EB, Tarawneh I, Nguyen HC, Harkless LB, Boulton AJM. A comparison of two diabetic foot ulcer classification systems: the Wagner and the University of Texas wound classification systems. Diabetes Care. 2001:24(1):84-8.

\section{Publisher's Note}

Springer Nature remains neutral with regard to jurisdictional claims in published maps and institutional affiliations.
Ready to submit your research? Choose BMC and benefit from:

- fast, convenient online submission

- thorough peer review by experienced researchers in your field

- rapid publication on acceptance

- support for research data, including large and complex data types

- gold Open Access which fosters wider collaboration and increased citations

- maximum visibility for your research: over 100M website views per year

At BMC, research is always in progress.

Learn more biomedcentral.com/submissions 